authors be placed in a separate genus, Cerastoma; others do not favor the division of the genus on sexual grounds.

Lacinius texanus, nov. sp. Length of body $3.6 \mathrm{~mm}$., width of body $2 . \mathrm{mm}$. Length of femur I, I. mm., femur II, 3.I mm., femur IV, 2. I mm., leg r, 6. mm. Color gray, mottled with white and brown; cephalothorax and dorsum of abdomen gray, mottled with brown and white spots; the vase-shaped mark barely visible; venter grayish white, a black line on the sides. Cephalothorax with some scattered spines and three large ones on the anterior margin, the median the largest; on the sides are three spines projecting between the legs. Eye-tubercle near the hind margin of the cephalothorax, nearly twice its diameter from the anterior margin, with two rows of four large spines. The posterior edge of each dorsal segment of the abdomen provided with a row of about ten white spines. Palpi quite large, white with some brown spots. The femur with about seven large and several smaller white spines on the under side, the end enlarged internally and covered with short, stiff, black hairs. The patella is prolonged, the inner side and prolongation being covered with short, stiff, black hairs. The tibia is enlarged at the end on the inner side and covered with similar hairs; on the under side are two white spines, like those on the femur. The tarsus (5th joint) is about as long as the two preceding, slightly curved, and provided with stiff hairs and a simple claw at end. Legs pale with brown bands; two on the femur, on the patella, tibia and metatarsus one each, and one at the base of the tarsus. The legs are all short, especially I and III; metatarsus I shorter than tibia I; there are no false articulations in any of the metatarsi. The coxae bear several (3-6) spines, one or two on each coxa being very large; several prominent spines at end of femur, patella and tibia. The femora are round except II which becomes quadrangular near tip; all the tibiae are quadrangular, each angle being furnished with a row of small spines; the patellae are somewhat four-sided, and the small spines are in rows, as also on the femora. The tarsi consist of many short joints. The tips of the claws of the mandibles are black. The structure of the coxae and sternum is similar to that of Oligolophus, but the sternum is a little shorter. The lateral pore is not visible from abuve.

Habitat, Eastern Texas.

\title{
THE LARVAL STAgES OF ICHTHyURA MULTNOMA Dyar.
}

BY HARRISON G. DYAR, BOSTON, MASS.

Ichthyura multnoma Dyar.

1892-Dyar, Canadian entomologist, xxiv, I79.

First larval stage.-Head round, shining black with a few hairs; width $0.5 \mathrm{~mm}$. Body somewhat flattened, with long pale and black hairs rising singly from large concolorous tubercles; color sordid grayish, tinged with dark vinous on joints $2,5,7,8,1$ I and 12 over the dorsum. Feet normal, the thoracic dark, the abdominal concolorous with the body. As the stage advances, the whitish spaces on the back become nearly white and the piliferous tubercles come out black and distinct, in three rows on each side. At the end of this, and of each following stage, the larva spins a house of thread and leaves in which it molts, and in which it remains during the succeeding stage, when not eating. The larvae are solitary.

Second stage.-Head as before; width 0.9 mm. Body flattened, with deep segmental incisures ; piliferous tubercles large, concolorous at first, but later black; setae short, black. Color blackish vinous except the dorsum of joints $3,4,6,9$, ro and 13 which is greenish 
white, containing tubercle $i$ and a very narrow dark dorsal line. The anal plate (i.e., joint 14 or the tenth abdominal segment) is vinous. Lateral and subventral tubercles pale. Thoracic feet black.

Third stage. - Head rounded, median suture deep, shiny black, hairy; width $\mathrm{r} .8 \mathrm{~mm}$. Warts rather large, each with a hair, and other somewhat shorter hairs arise from the body. Color vinous black with pale yellow dorsal patches on joints 3 and 4, 6, 9 and ro and $\mathrm{I} 3$ anteriorly, enclosing warts $\mathrm{i}$ and ii. A dark dorsal line, each side of which are a few yellow mottlings on the dark segments; subventral warts largely yellow, the others concolorous with the markings except row i which is dark on the yellow segments. Setae all blackish. Later, joints 5 and $\mathrm{I} 2$ are seen to be a little enlarged dorsally, a narrow, broken, waved line appears along warts $i$ in the yellow markings, the yellow patch on joints 9 and Io extends faintly on joint $\mathrm{I}$, there is a broken, irregular, yellow, superstigmatal line, distinct only on the yellowmarked segments and some rather more continuous yellow mottlings along the substigmatal ridge.

Fourth stage. - Head rounded, clypeus depressed, median suture deep; hair short, dense, white; color black, slightly shiny, brownish centrally in the depression around the median suture; width $3.0 \mathrm{~mm}$. Warts rather large, rows $i$ and ii on joints 3, 4, 6, 9, Io and 13 and all the subventral warts yellow, the others black. Joints 5 and 12 enlarged dorsally, velvety black. Color purplish black, a broad, yellow, dorsal band except on joints 5 and 12 , containing a broken, triple, dorsal line, fainter on joints 7,8 and ir. The rest of the body is purplish black, the subventral region included. Hair dense, white, consisting of fine short hairs from the body, with single, slightly longer and larger ones from the warts. As the stage advances a marked change takes place. A broad pale gray dorsal band, containing very faint triple dark line, obsolescent and broken; warts $i$ and ii orange, except on joints 2 and 5, row ii on joints $3,4,6,9$, ro and 13 broadly orange; a broad, pale bluish, subdorsal band, heavily mottled with vinous black; joints 5 and $\mathrm{I} 2$ dorsally, and lateral spots on all segments (most distinct on joints 3-5), velvety black. A broad, broken, deep orange, stigmatal band, divided by an irregular black stigmatal line and consisting of orange spots spreading from the warts of rows iv and $\mathrm{v}$ and adjacent mottlings, barely confluent. Venter blackish; thoracic feet shiny black.

Cocoon.- Not different from the house made at the end of each stage, except that there are a few transverse threads to support the pupa.

Pupa.-Small but robust. Dorsal outline arched, ventral nearly straight, rounded at both ends; cremaster, a long spine of even thickness throughout. Smooth, shining; abdomen very slightly punctured. Color red-brown, darker ventrally and dorsally, nearly black on the thorax and cases, with a green tinge on the latter. Length $13 \mathrm{~mm}$.; width $4.5 \mathrm{~mm}$. There are two broods each year.

Food plant.-Willow (Salix).

Habitat.-Oregon and Washington west of the Cascade range and, probably, also western British Columbia. Found by Prof. O. B. Johnson at Seattle, Wash. Larva from Portland, Oregon.

\section{The Morphology and Phylogeny of In- SECTS.}

The Annals and magazine of natural history published in December last a translation of the concluding general portion of a memoir by $\mathrm{N}$. Cholodkowsky on the embryonal development of Phyllodromia germanica (Mém. acad. St. Pétersb., 7 sér., v. 38, 189r) which closes with the following summary. It will prove interesting and suggestive to American entomologists.

1. The head of insects contains more than four protozonites, probably six, of which one is preoral, but the rest are postoral. 

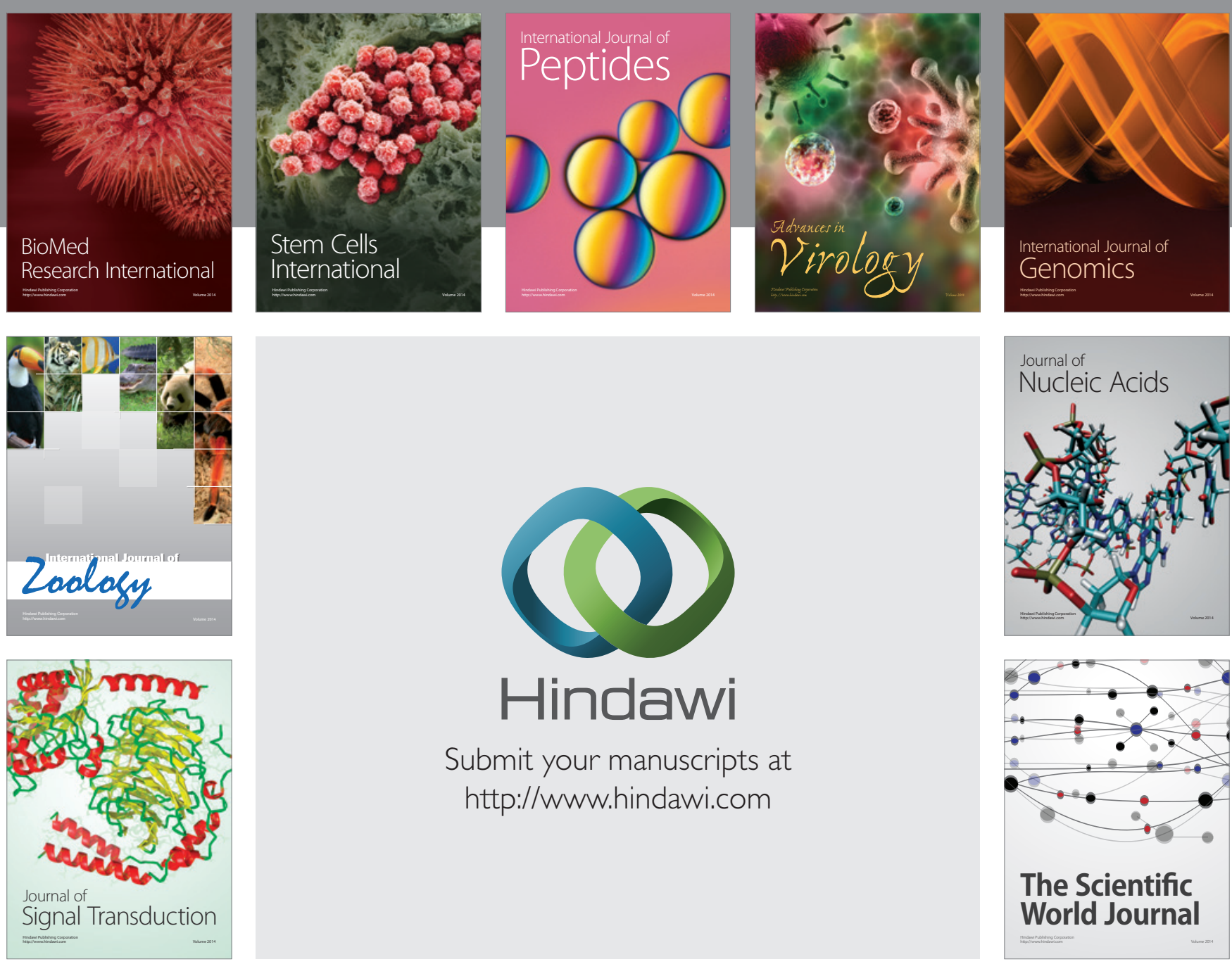

Submit your manuscripts at

http://www.hindawi.com
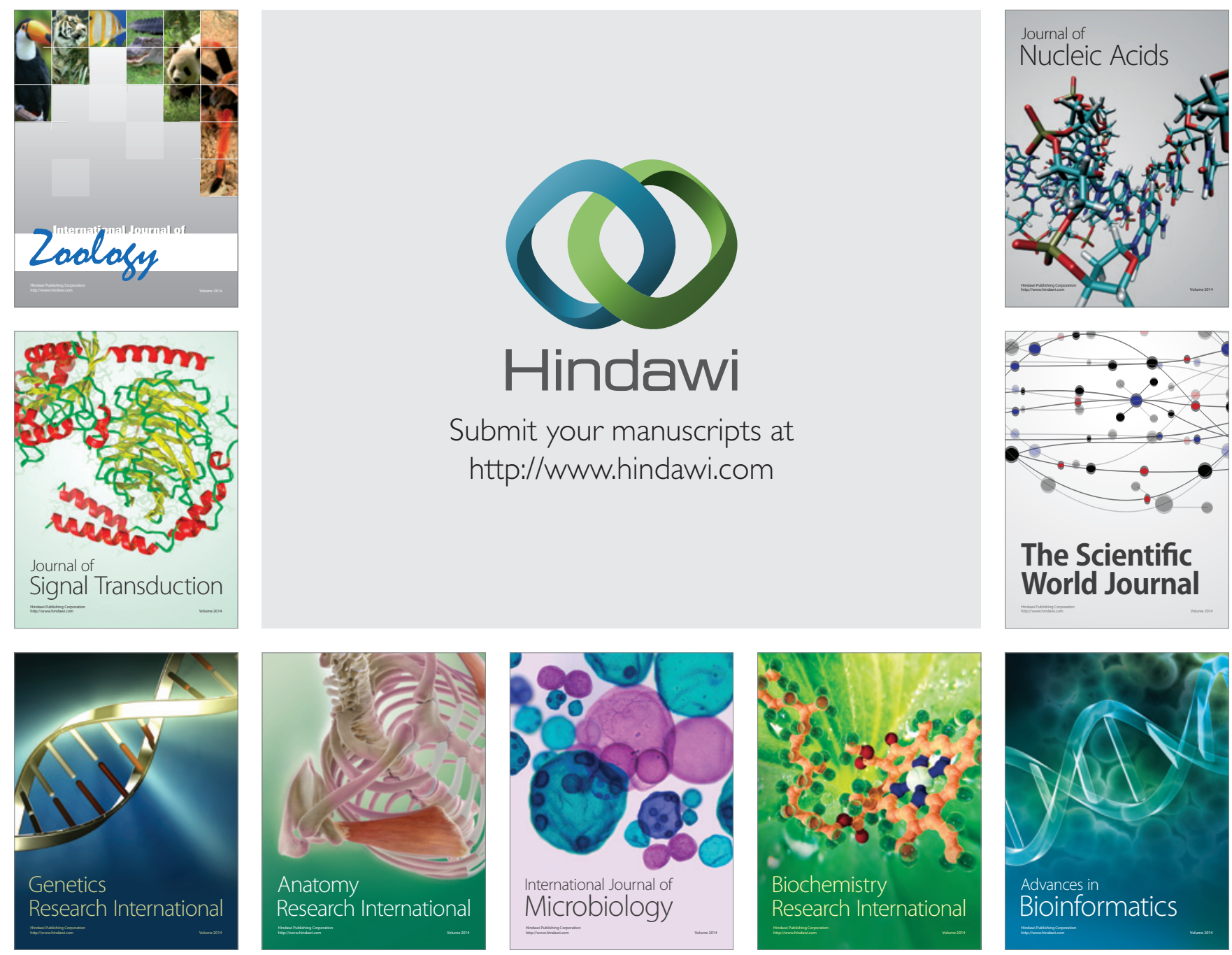

The Scientific World Journal
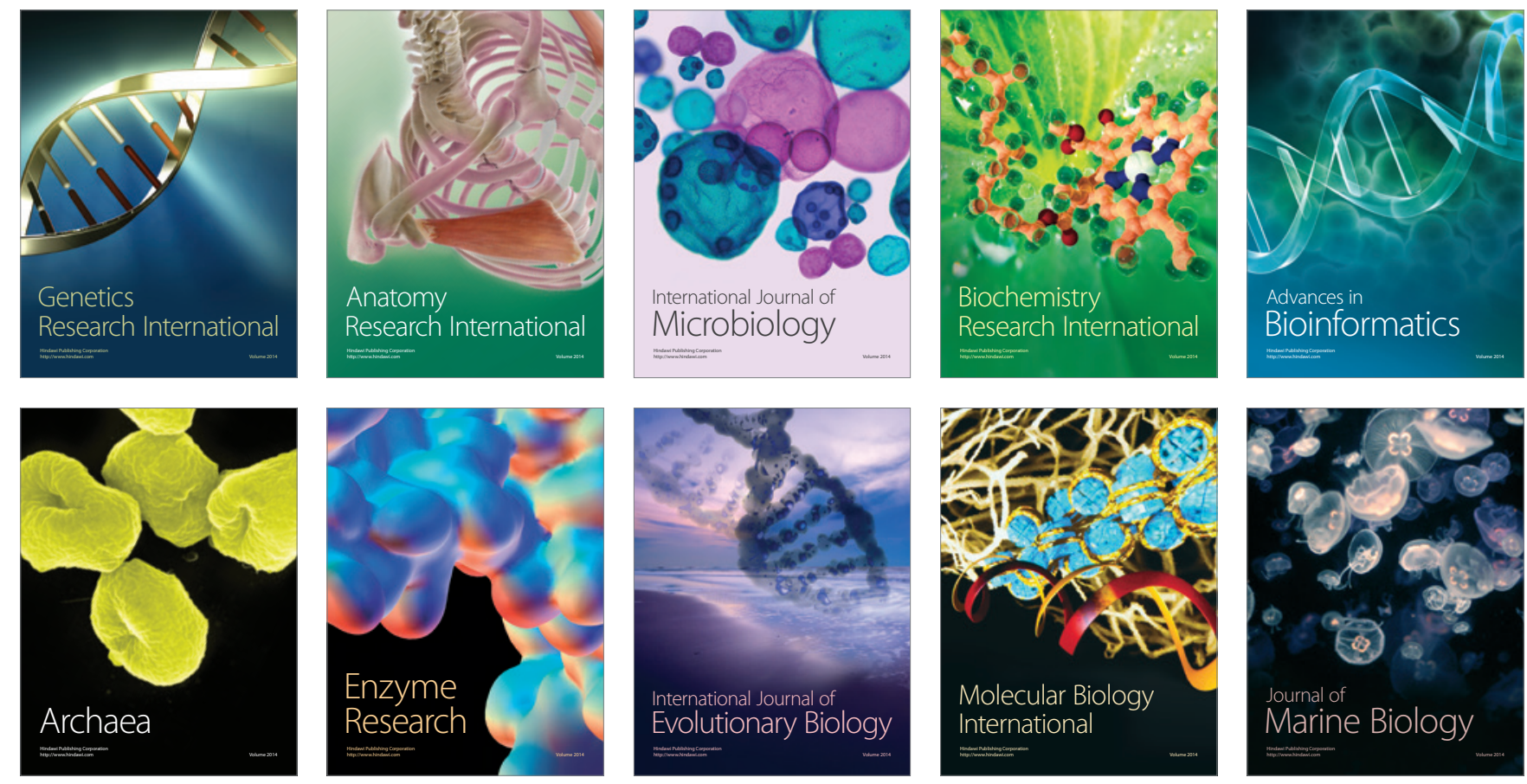